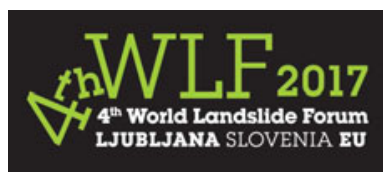

\title{
Public Awareness and Education Programme for Landslide Management and Evaluation Using a Social Research Approach to Determining "Acceptable Risk" and "Tolerable Risk" in Landslide Risk Areas in Malaysia (IPL-194, IPL-207)
}

\author{
Ab Rashid Ahmad, Zainal Arsad Md Amin, Che Hassandi Abdullah, \\ and Siti Zarina Ngajam
}

\begin{abstract}
Although early records of landslides in Malaysia have existed since the beginning of the last century, national attention on landslides increased in earnest in the wake of the 1993 Highland Towers landslides. In 2003, an economically devastating rockslide in Bukit Lanjan led to the establishment of the Slope Engineering Branch (Cawangan Kejuruteraan Cerun-CKC). One of CKC's first achievements upon formation was to carry out a National Slope Master Plan study to reduce risks and losses from landslides. One of the studies explores and devises methods for assessing risk that combine traditional and risk-based approaches. It introduces a risk assessment-based approach that looks beyond the fulfilment of Factors of Safety; it evaluates a slope based on its risk or probability of slope failure occurrence and assesses the consequence or damage caused by the failure. Most significantly, it compares the derived risk assessment results with the acceptable risk level of the public and residents. In essence, it becomes a decision-making tool for slope planners and developers to determine whether to proceed with the construction of a new slope or how much mitigation work should be put into an existing failing slope. One of the study components, Public Awareness and Education, launched a national awareness and education campaign to get create awareness of landslide risks and mobilize various stakeholders in the public, private, civil society and community levels into taking proactive measures for mitigation and prevention. It culminated in a programing conveying four main key messages, which are "Learn, Monitor, Maintain and Report".
\end{abstract}

\section{Keywords}

Public awareness $\bullet$ Slope safety $\bullet$ Learn $\bullet$ Monitor $\bullet$ Maintain $\bullet$ Tolerable risk $\bullet$ Acceptable risk $\bullet$ Risk criteria $\bullet$ ALARP $\bullet$ Quantitative risk analysis $\bullet$ Societal risk $\bullet$ Economic losses

A. Rashid Ahmad (ه) - Z.A.M. Amin

C.H. Abdullah · S.Z. Ngajam

Public Works Department (Jabatan Kerja Raya Malaysia), Slope Engineering Branch Ministry of Works, Jalan Sultan Salahuddin, 50582 Kuala Lumpur, Malaysia

e-mail: ABRashidAhmad.jkr@1govuc.gov.my

Z.A.M. Amin

e-mail: ZArsad.jkr@1govuc.gov.my

C.H. Abdullah

e-mail: Hassandi.jkr@1govuc.gov.my

S.Z. Ngajam

e-mail: SitiZarina.jkr@1govuc.gov.my

\section{Introduction}

This paper will discuss two of the important elements in Malaysia's National Slope Master Plan (NSMP) - the Public Awareness Education Program and the Loss Assessment Measures.

Records of landslides in Malaysia have existed since the beginning of the last century, but national attention to landslide hazards increased in the wake of the 1993 Highland Towers landslides. In 2003, an economically devastating 
rockslide in Bukit Lanjan led to the establishment of the Slope Engineering Branch (Cawangan Kejuruteraan CerunCKC) of the Public Works Department Malaysia (National Slope Master Plan 2009-2023 (2009)).

The Slope Engineering Branch ran a public awareness and education programme to create awareness among the public to minimize the effects of landslides. The objective was to create a society that emphasized risk reduction and resiliency to landslide disasters. Through outreach activities, the programme identified and disseminated information on actions and measures that can be taken by community members, as well as by government and private owners of slopes. As it is human nature to focus on safety only after a disaster happens, the public awareness program aims to get people thinking about the slope safety before any landslides occur.

On other hand, when it comes to urban development on slopes, there are many requirements and guidelines stipulated by local, state, and federal authorities. However, these stipulations are technical and engineering-driven, such as factors of safety, buffer zones, and maximum berm height.

However, stakeholders in slope management should extend beyond land-use planners and technical personnel. Members of the public and communities in hillside areas that experience the consequences of failing slopes, whether it be loss of property, depreciation in real estate value, or even loss of lives, have to be included. Thus, slope planning approaches that incorporate the requirements of both the technical engineer and hillside residents are needed.

This study explores and formulates methods for assessing risk that combine conventional and risk-based approaches. It introduces a risk assessment-based approach that looks beyond the fulfilment of factors of safety; it evaluates a slope based on its risk or probability of slope failure occurrence and assesses the consequence or damage caused by the failure.

Most significantly, it compares the derived risk assessment results with the risk level considered acceptable by the public and residents. In essence, it becomes a decision-making tool for slope planners and developers to determine whether to proceed with the construction on a new slope or how much mitigation work should be put into an existing failing slope.

This study is an interdisciplinary endeavour that encompasses geotechnical engineering, risk management, mathematical modelling, psychology and social sciences, and economic assessment. The objective of the study is the application of the risk assessment methodology for two practical purposes:

(1) Guiding the design and approval of new developments on slopes, and
(2) Prioritizing treatment and monitoring efforts for existing developments.

\section{Public Awareness and Education Program}

Although the main target groups of the program were the communities-at-risk and the general public, there were other target groups consisting of the state and local governments, private slope owners, media, universities and schools (JKR 2010).

The objective of the awareness program was to convey two key messages to the public. The first was to let the public know that there is a body of useful information that is available to the public on the phenomenon of landslides and tips on monitoring and maintenance. The second is that there is a government agency dedicated to safeguarding the interest of public safety.

These messages were encapsulated in the campaign theme of "Learn, Maintain, Monitor and Report" and all activities of the awareness program were centred around this theme. The motif that tied all these activities together was the slogan "Safe Slopes Save Lives", courtesy of the Geotechnical Engineering Office in Hong Kong.

\section{Learn}

Before any community action can be taken, residents and the general public needed some knowledge of the concepts of slope safety. Through seminars and public talks, the public was given a briefing on slopes and landslides. Residents were taught about what is a slope, types of landslides, factor of landslides, triggers of landslides and key concepts on slope water control, slope cover, retaining walls and geological aspects. This basic knowledge enabled residents to better understand the reasons behind the measures prescribed by $\mathrm{CKC}$ and ensure the sustainability of the programme.

\section{Monitor}

Although landslides sometime occur without warning, there are usually signs which residents in hillside communities overlook, as they do not recognize the signs of landslides. With urban development encroaching onto hillsides, monitoring for signs of slope failures is vital to slope safety. Man-made slopes in particular are becoming more and more prevalent and they need to be routinely checked. For this purpose, CKC compiled a collection of images showing 
signs of landslides as they appear on and around the slopes, inside and outside houses and buildings. Armed with this knowledge, residents are able to carry out visual slope inspections on slopes within their community.

\section{Maintain}

Even well-designed slopes will fail if they are not maintained. Maintenance is simple to do, yet often neglected. Proper maintenance can make the difference between safety and disaster. Maintenance starts with an inspection of a slope. This can be done by residents, local authorities, and private slope owners with some basic knowledge of maintenance guidelines.

One of the key messages for this activity is that there must be a regular schedule of maintenance to be done by laymen residents and by professional engineers. Ideally, there are three different kinds of maintenance to be undertaken: simple maintenance such as clearing drains and returfing slope vegetation, which can be done by residents, and the other is a more technical slope inspection by qualified engineers who inspect slope features such as rock anchors and retaining walls. The third kind is inspection of water pipes for leakages and seepage.

While the onus of maintenance falls on the slope owners, community members are encouraged to engage in maintenance as it affects their livelihood and safety.

\section{Report}

The key message of monitoring for signs of landslides would not be effective if the observations were not reported to the relevant authorities for follow-up repair or mitigation action. Thus, residents are told to report any signs that are deemed to require action, such as broken drains that allow water to seep into the slope. Usually the authority to be contacted is the engineering department of the local authorities, as they deal with infrastructural matters on public property. If the slope in question is on private property, the local authority would contact the land owner for action. In some cases, where there is no response from the land owner, a Notice to Take Action, would be issued. As a slope agency, $\mathrm{CKC}$ receives its share of reports from the public, and in these cases $\mathrm{CKC}$ will direct the case to the appropriate agency or land owner.

\section{Methodology of the Program}

To provide maximum exposure, the methodology of the programme entailed presenting its messages and material through various mediums.

\section{Logo and Slogan}

There is the adage that the messenger is just as important as the message. If people distrust the agency or are not aware that it exists, then the messages will not be received by the target audience. During a pre-programme survey, many respondents in target areas revealed that they were not aware of the existence of CKC. Others said that the Public Works Department (JKR) as a whole does not disseminate information to the public. To create the image that $\mathrm{CKC}$ 's role is to engage and teach residents on slope safety, a friendly face was put onto the agency. After several candidate cartoon depictions of a mascot, a youthful, energetic, pan-Asian JKR engineer was created as a logo. He is seen leaning forward to meet residents halfway and to convey an attitude of attentiveness. Mr. JKR Logo is shown in Fig. 1.

"Mr. JKR" is surrounded by the slogan 'Safe Slopes Save Lives", courtesy of GEO Hong Kong, which encapsulates the same objective and goal of saving lives. This underscores CKC's philosophy that slope safety is not an engineering issue, but a people and quality of living issue.

\section{Printed Material}

A series of brochures written in Bahasa Malaysia and English was created to convey information on the four key messages of the campaign which is "Learn, Monitor, Maintain and Report". Designed with bright colours and replete with illustrations and photos, the brochures provide hands-on, action-oriented tips and guides to readers. Figure 2 shows the brochures written in Bahasa Malaysia and English.

Another set of publications created were posters written in Malay Language to post up in public places ('Learn, Monitor, Maintain, And Report). The posters are shown in Fig. 3.

\section{Advertorials}

The mass-media plays an important role in raising the awareness of the public. During the peak months of the monsoon season, when landslides are likely to happen, CKC publishes a series of advertorials in newspapers in four main languages,

Fig. 1 Mr. JKR Logo was created to give friendly face to the message, as well as to the image of JKR

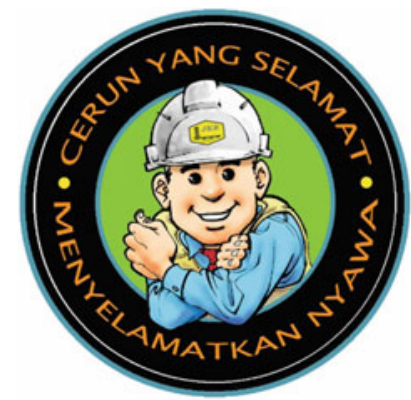




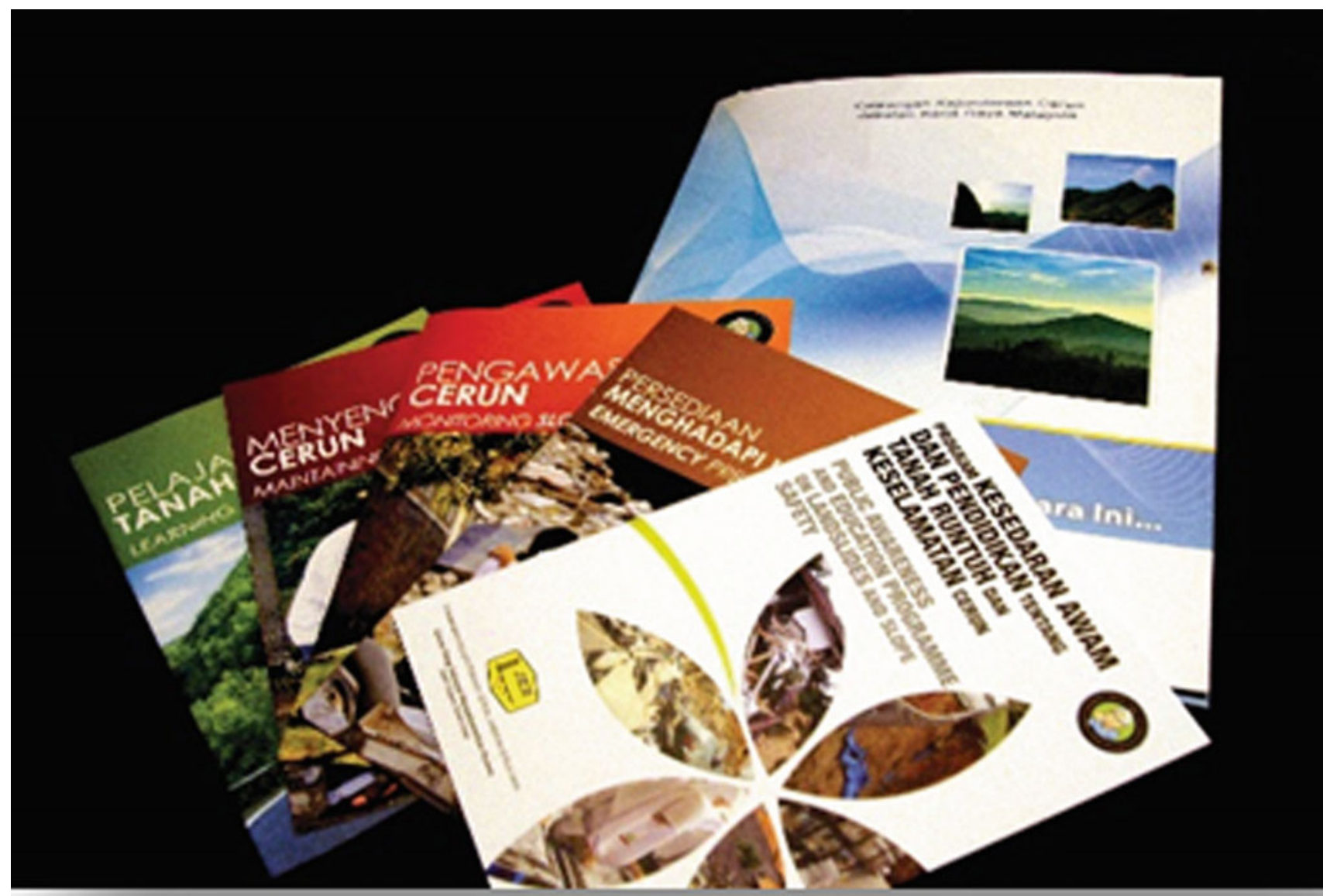

Fig. 2 A series of brochures used during the public awareness campaign

which are English, Malay language, Mandarin and Tamil languages to renew awareness and provide useful information to readers nationwide in upgrading their surveillance of slopes and signs of landslides. Advertorials are shown in Fig. 4.

\section{TV Commercials}

In addition to the print media, $\mathrm{CKC}$ has used broadcast media to run several seasons of $\mathrm{TV}$ commercials to raise awareness of slope safety. The commercials are produced to create awareness among people about the importance of being vigilant and keeping an eye on the environment, especially those who live on risk areas such as slopes. The commercials insert scenes of learning and teaching to have a deep impact on the audience watching the commercials. It is hoped that by watching the commercials, people will acquire the knowledge to detect signs before the occurrence of landslides, know what should be done if there are signs in their area, and what actions should be carried out in the event of a landslide near their resident area.
As with the advertorials, the infomercials are run at the end of the year during the monsoon season.

\section{Awareness Billboards}

To make slope monitoring, maintenance and reporting a regular practice in landslide-prone areas identified in the National Slope Master Plan, billboards near at-risk communities have been set up to remind residents to keep an eye out for the signs of landslides and report them to the authorities. This message is conveyed to urban audiences. For the rural communities, a different message is provided. Slope construction in rural and agricultural areas is not as regulated as in the urban areas, and there have been incidents of slopes that have been constructed not following proper guidelines. For this audience, a sterner message has been crafted, saying that improper construction of slopes on unauthorized land can lead to landslides.

Billboards are merely reminders of prescriptive actions, and of themselves will not change social behaviour unless 


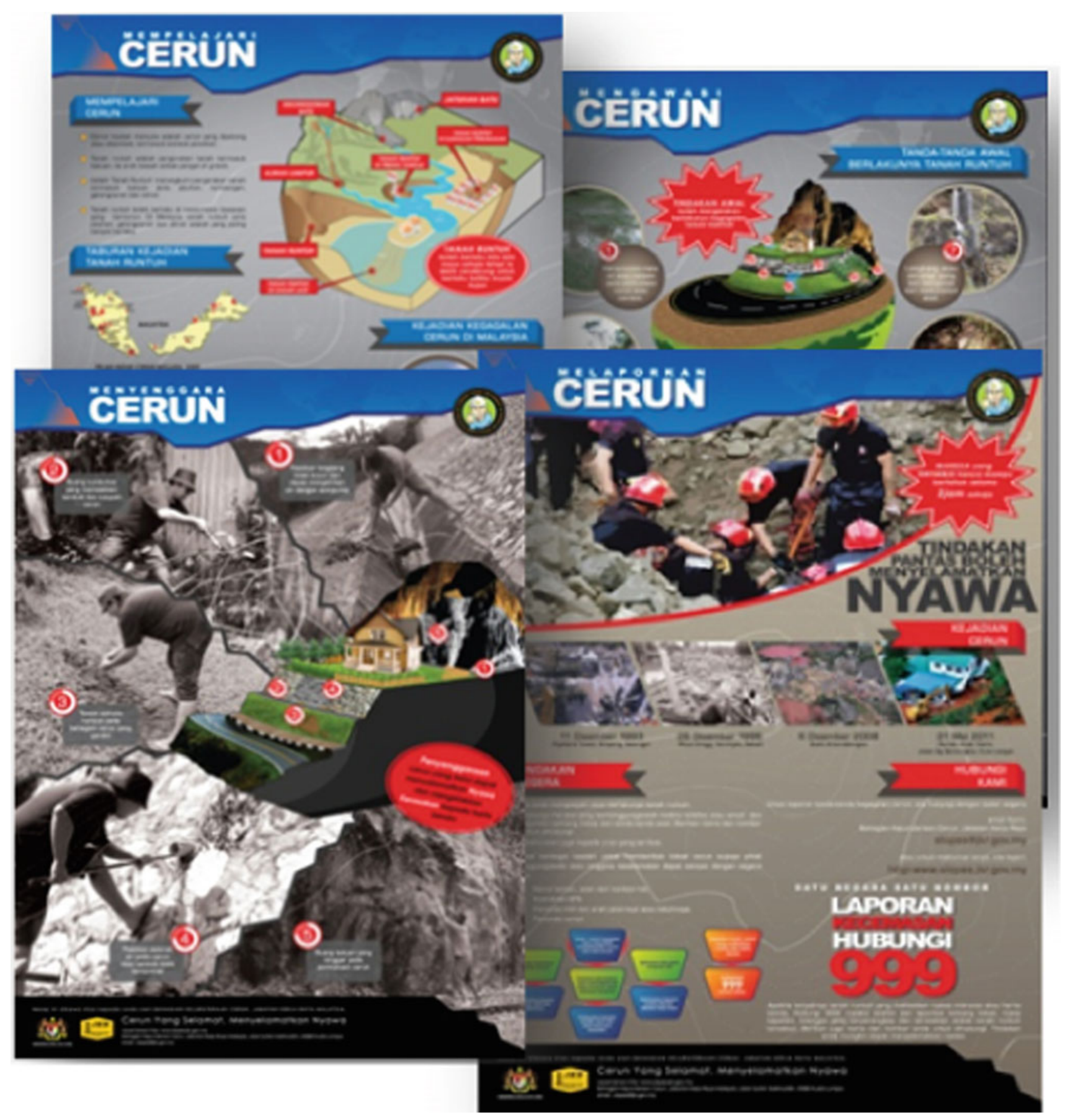

Fig. 3 A series of posters used during the public awareness campaign 


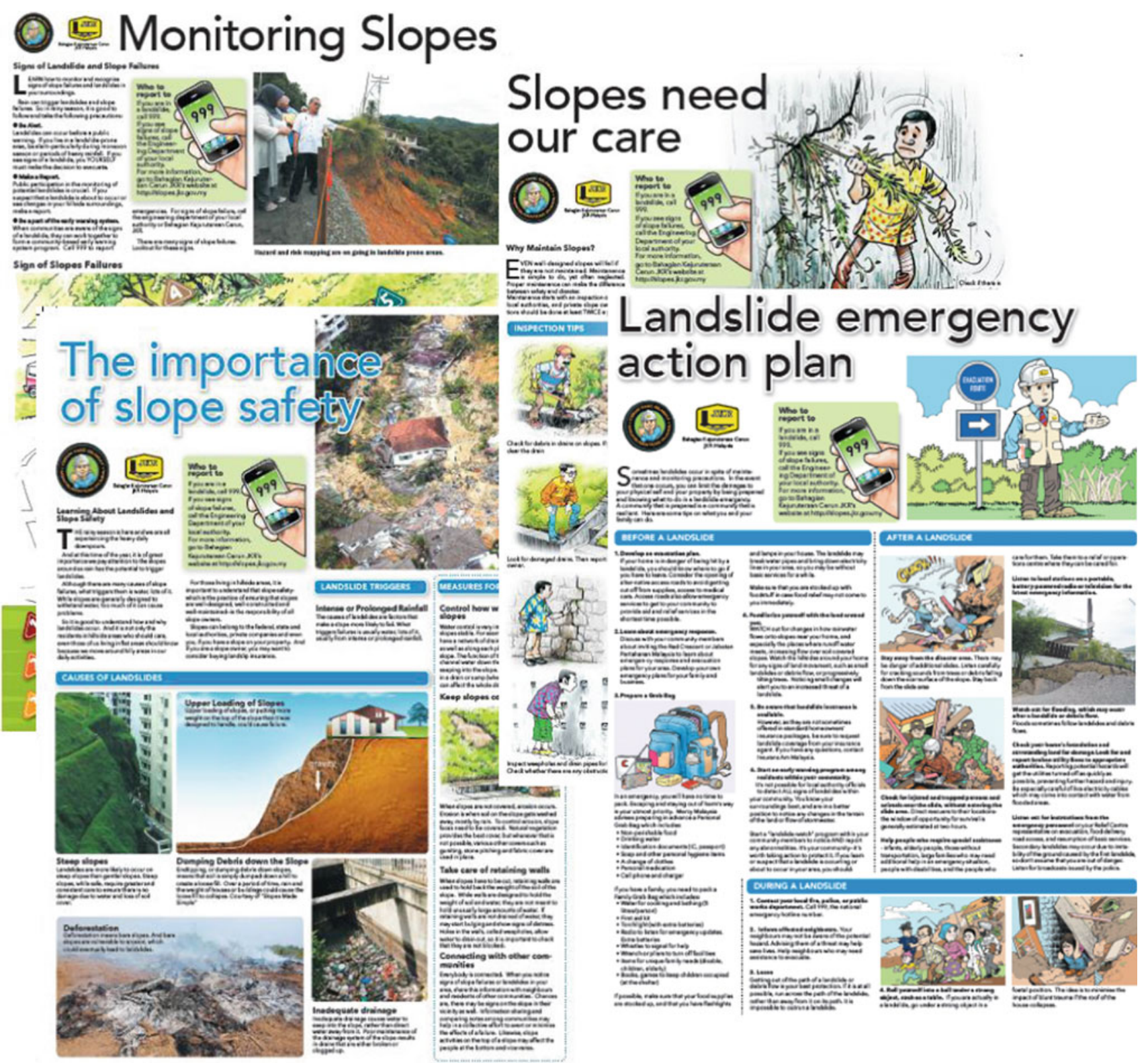

Fig. 4 A series of advertorials published in newspaper

accompanied by grassroots and outreach programs. However, the billboards have garnered attention by media whenever a landslide or mudflow incident occurs in the adjacent area. In Bukit Antarabangsa, where the billboard greets all residents and visitors coming up a particularly rocky slope which is the entrance to the housing developments, it serves as reminders to always keep a vigilant eye. Figure 5 shows the example of billboard displayed during the campaign.

\section{Evaluation Determining "Acceptable Risk" and "Tolerable Risk" in Landslide Risk Areas in Malaysia}

\section{Methodology}

As the practice of utilizing risk assessment using F-N charts is new in Malaysia, a suitable and proven method- 
PANTAU DAN LAPOR

UNTUK KESELAMATAN

\section{CERUN}

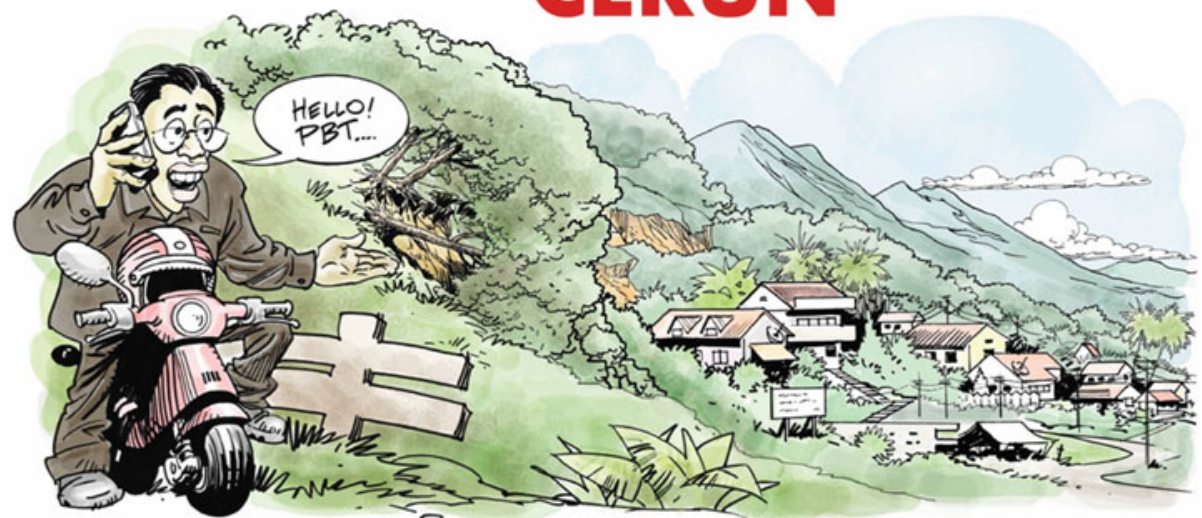

\section{CERUN YANG SELAMAT, MENYELAMATKAN NYAWA}

\section{PENANAMAN HARAM BOLEH MENYEBABKAN} TANAH RUNTUH

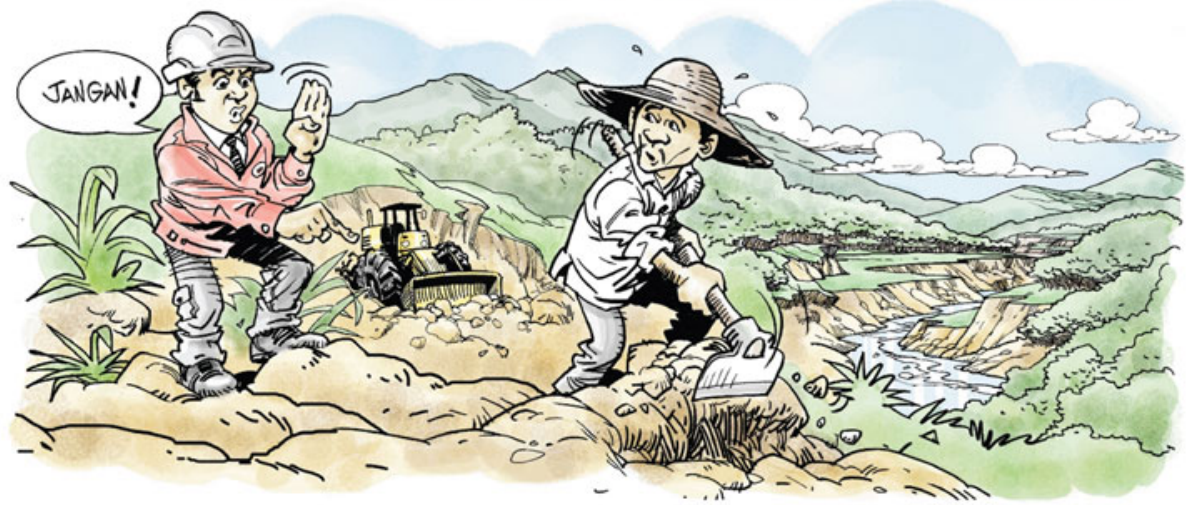

\section{CERUN YANG SELAMAT, MENYELAMATKAN NYAWA}

Info lanjut di http://slopes.jkr.gov.my 
Fig. 6 Risk management flowchart

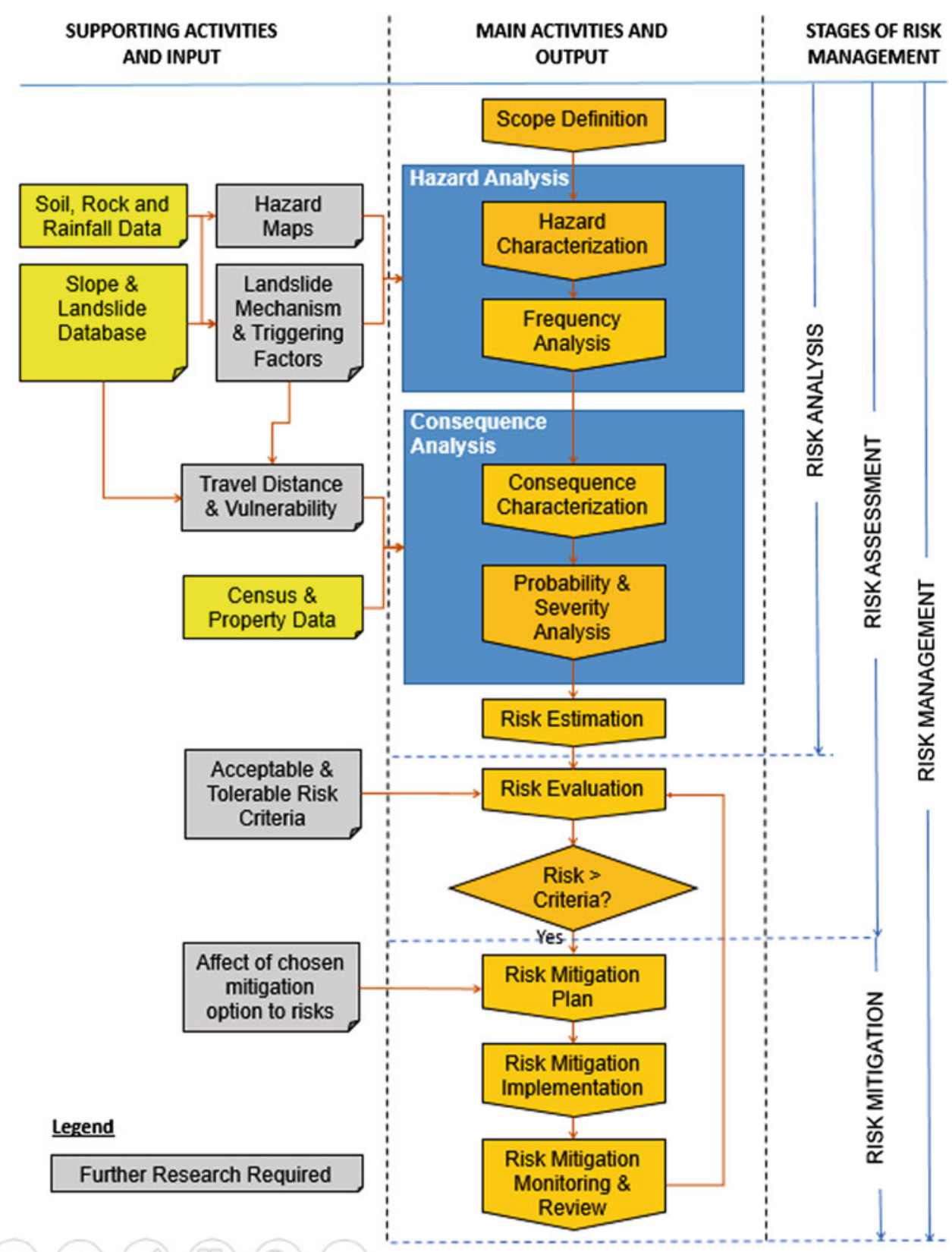

ology had to be researched, evaluated, and tested. An extensive literature review led to the development of a methodology that incorporates quantitative risk assessment (QRA), historical risk assessment, psychometrics, risk perception and risk criteria theories, loss assessment quantification, and cost-benefit analysis (JKR 2015).

The methodology selected was based on the proceedings of the International Conference on Landslide Risk Management, which is a collection of risk management papers edited and written by seasoned geotechnical risk assessment (Finlay et al. 1999). Figure 6 shows the localized framework based on their model.
The main activities of the study are to:

(i) Calculate the risk assessment line representing the probability of slope failure and its consequences (called the projected "F-N curve").

(ii) Identify the acceptable and tolerability risk thresholds of stakeholders (called the "risk criteria curve").

(iii) Juxtapose both curves on the F-N chart and determine whether the risk level of the slope project falls within the tolerable, acceptable, or unacceptable range as defined by the resident stakeholders. 
(iv) Determine which option of action to take, depending on the outcome of the F-N chart.

(v) Recommend whether the proposed slope project is economically feasible if further re-designs or mitigation works are required.

These activities are carried in the following key deliverables and actions.

\section{Determining Mortality Rates}

One of the objectives of this study is to determine the actual frequency or the probability of failures and fatalities. Plotted on an accumulated frequency-fatality (F-N) chart on a $\log$-log scale, the risk and likelihood of failure can be clearly projected. This is done by using historical data on landslide events with fatalities. Figure 7 indicates the FN Chart for Malaysia as compared with other countries.

\section{Determining Rate of Economic Losses}

It has been observed that some of the most devastating landslides in Malaysia have been those incurring major economic losses, not high fatalities. Thus, the process for determining the rate of economic losses have been discussed in this study. It follows the same methodology as for F-N curves, as a reference model has not been addressed in worldwide studies and warrants further research in this area Fig. 7.

\section{Identifying Social Survey Methodology and Design}

The F-N curve alone merely shows the frequency and consequences of fatal landslide events. To see whether these are acceptable by the general public or by specific communities, they need to be compared with risk criteria, which are curves on the F-N chart that determine the thresholds for acceptable, tolerable, and unacceptable risks. Interpretation of the curves on the F-N chart is fairly straightforward: any part of the F-N curve that falls under the acceptable risk criteria is fine; no preventive or mitigation actions are needed.

Parts of the F-N curve that fall into the tolerable range needs to be worked on; they are only tolerable as long as there is some mitigation or preventive action being taken. And finally, anything that falls above the unacceptable curve is out of the question by the stakeholders; action to relocate or engage in major mitigation work is required. These risks, experienced by many in a population, is called societal risk.

Coming up with the risk thresholds on the other hand is not so straightforward. To identify the social research

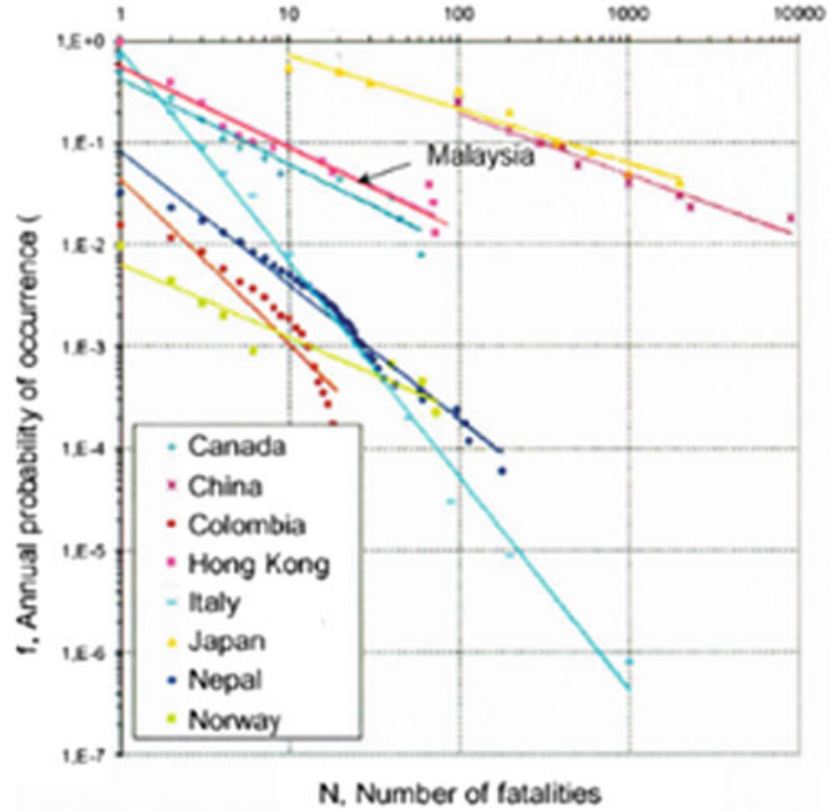

Fig. 7 F-N chart for Malaysia compared with other countries

approach, various theories and methods of social research were reviewed. After reviewing numerous revealed and expressed preference approaches, a psychometric approach modelled after a study by University of New South Wales Ph.D. recipient P. J. Finlay and Professor Emeritus Dr. Robin Fell was selected. The study, which encompasses a survey questionnaire applied to nine communities in Australia and Hong Kong, was adopted for application in Malaysia.

\section{Deriving Risk Criteria Thresholds for Malaysia}

Risk criteria are locale-specific and the same risk criteria cannot be applied from country to country, or even from region to region, as the thresholds depend on feedback from the population being surveyed.

The risk criteria curve used in Hong Kong for example cannot be applied in Malaysia. For the risk criteria in the study area, which consists of communities in Ulu Klang (representing urban communities) and Ulu Langat (for rural communities), a combination of two derivation approaches were used.

Derivation entails taking the results from the survey questionnaires on acceptable frequency and number of fatalities acceptable to people living in these areas, and converting them into a chart. One approach is the Risk Matrix method used in hazard-sensitive industries such as the aviation industry, and the other is the Risk Criteria method used by Finlay and Fell. 
Both methods produced the same results and validated the resultant risk criteria curves. They shall be called the Interim Malaysian Risk Criteria, as they represent the acceptable and tolerable levels for the study areas of Ulu Klang and Ulu Langat.

\section{Determining Actions to Be Taken by Authorities}

The results of the F-N chart will be reviewed by land-use planners and approving urban development agencies, as well as by technical agencies responsible for undertaking repair and rehabilitation works. These activities will be largely affected by financial considerations and whether the cost of repair or mitigation will be commensurate with the benefits derived (i.e., avoiding the losses). For this, a cost-benefit analysis needs to be carried out.

\section{Financing the Actions}

All preventive, mitigation, or rehabilitation options require financing. Thus, a study was conducted to determine the willingness to pay by the residents living in the affected hillside communities. Using the contingent valuation method, the willingness to pay was derived using survey questionnaires on how much residents were willing to pay for different solutions that correspond with varying risk levels and resultant 'savings in lives'.

\section{Framework for Risk-based Slope Decision Making in Malaysia}

Finally, a risk-based approach to slope management cannot materialize without a formal framework for which stakeholders, from developers to local authorities to communities, can follow. Thus, a framework is proposed which shows the steps from the preparation of the Development Order by the developer, to the review and approval process by the hillside and highland review committee at the local authority level, to final review by the One Stop Centre at the state and local authority levels.

\section{Findings}

Findings show that the tolerable and acceptable risk criteria for the study areas in Malaysia are higher than the interim Hong Kong criteria. The risk criteria derived from this area shall be called 'Interim Malaysia Risk Criteria'. The tolerable frequency for Hong Kong is one landslide with fatalities every 1000 years, while the tolerable threshold for the
Malaysian study areas is once every 50 years. Figure 8 shows The Interim Risk Criteria for Malaysia.

Using the loss assessment data from the National Slope Master Plan, the analysis suggests that economic losses amounting to RM 1 billion per annum is possible once in a hundred years.

In determining the mortality rates the study indicates that the landslide mortality rate for Malaysia is the same as Hong Kong. When plotted on a cumulative frequency-fatality (F-N) chart, the equation for the curve could be written as $\mathrm{F}=1.99 \mathrm{~N}-1.15$. This means that on average in Malaysia 2 fatal landslides occur annually, and a landslide claiming more than 100 lives would occur once in a hundred years.

Urban residents were willing to pay between RM151 to RM305 annually for maintenance or repair works, while rural residents could commit RM22 to RM112 annually. This shows that Malaysians are willing to pay for safer slopes.

\section{Conclusion}

CKC's awareness and education programme has had an impact in ways that extend beyond outreach to the communities. It has created awareness among the local authorities, some of which have instituted their own slope units and have started requesting further training to enhance their existing knowledge and know-how in slope management. CKC's ultimate goal is to mainstream slope safety so that it impacts all relevant aspects of land-use planning and governance. However, this is an ongoing process and as such, it is important that it continues its programme to sustain the momentum that it has started. All programs on awareness and education are focusing on the element of "Learn, Maintain, Monitor and Report" which demand the participation of general public to avoid any untoward incident due to landslides.

A risk-based approach is a decision-making instrument that can provide decision makers with more information about a slope. Following the adage that even with a high Factors of Safety (FOS), the probability of failure can be high:

i. For a nationwide F-N curve, historical data is used; for site-specific F-N curves, a Quantitative Risk Assessment (QRA) approach is used

ii. FOS will still be used in risk assessment of slopes, but we can improve on risk reduction by including the F-N chart method

iii. The Interim Malaysian F-N curve can replace or eliminate the buffer zone requirement, which is a point of contention between developers and approving authorities

iv. The Interim Malaysian risk criteria is higher (more accepting of risks) than the Hong Kong risk criteria

v. A deterministic approach is used for QRA, as opposed to the static probability approach. ALARP (As Low As 
Fig. 8 Malaysian F-N curve with risk criteria from study area

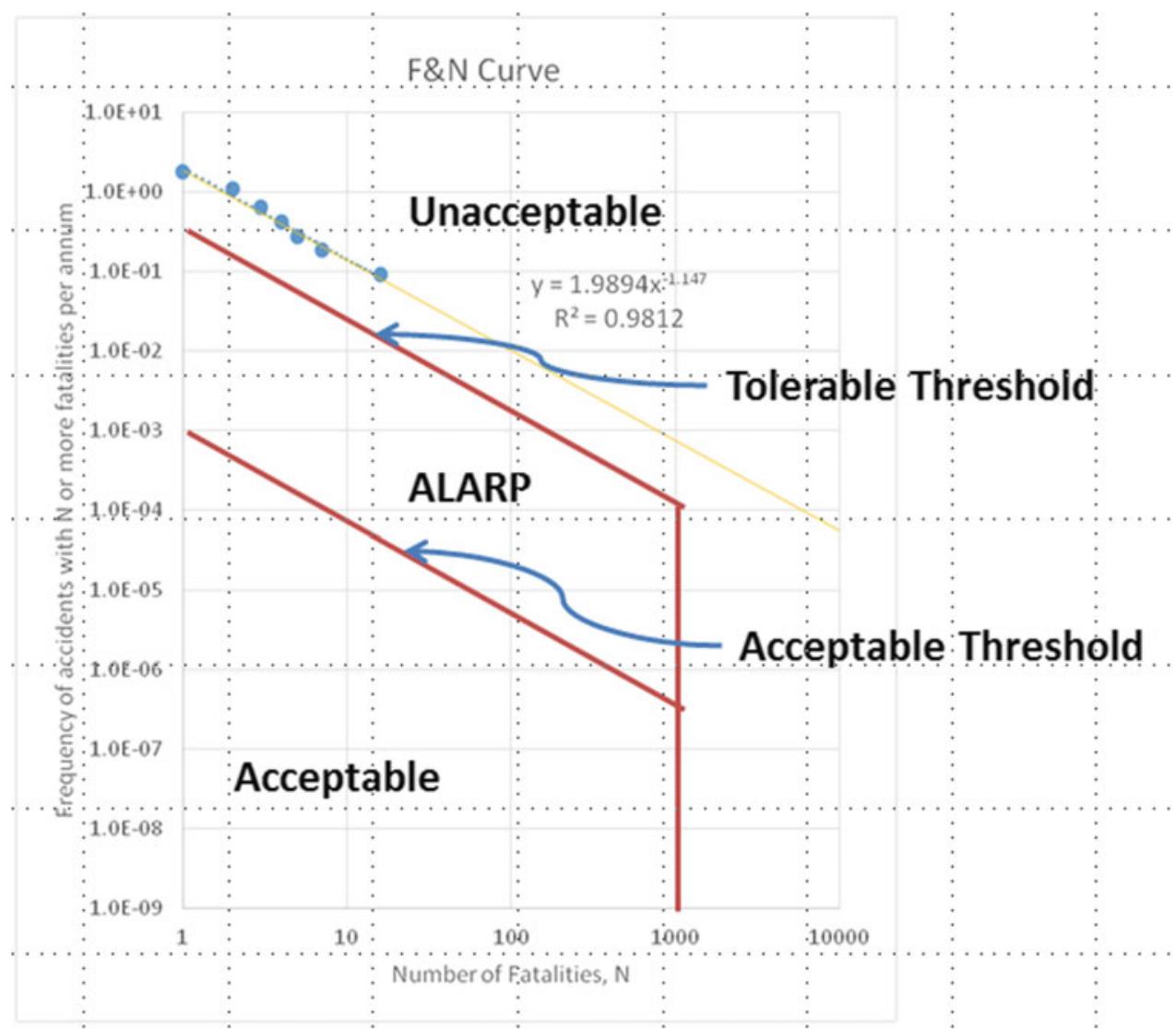

Reasonably Possible) is the same as tolerable risk, except that it takes into consideration that the costs of reducing risk should never exceed the benefits

vi. More surveys in other parts of the country should be carried out to develop national risk criteria.

\section{References}

Finlay PJ, Mostyn GR, Fell R (1999) Landslide: prediction of travel distance and guidelines for vulnerability of persons. In: Proceeding of 8th Australia/New Zealand conference on geomechanics, Hobart. Australian geomechanics, vol 1. pp 105-113

JKR (2010) Final report public awareness and education program on landslide and slope safety. Public Works Department Malaysia, Kuala Lumpur

JKR (2015) A study on determining "Acceptable Risk" and "Tolerable Risk" criteria. Public Works Department Malaysia, Kuala Lumpur National Slope Master Plan 2009-2023 (2009), Public Works Department Malaysia, Kuala Lumpur
Open Access This chapter is licensed under the terms of the Creative Commons Attribution 4.0 International License (http:// creativecommons.org/licenses/by/4.0/), which permits use, sharing, adaptation, distribution and reproduction in any medium or format, as long as you give appropriate credit to the original author(s) and the source, provide a link to the Creative Commons license and indicate if changes were made.
The images or other third party material in this chapter are included in the chapter's Creative Commons license, unless indicated otherwise in a credit line to the material. If material is not included in the chapter's Creative Commons license and your intended use is not permitted by statutory regulation or exceeds the permitted use, you will need to obtain permission directly from the copyright holder. 